\title{
Ischaemia/reperfusion in the posthypoxaemic re-oxygenated myocardium: haemodynamic study in the isolated perfused rat heart
}

\begin{abstract}
Antonio Corno,* Roberto Motterlini, Laura Brenna, Francesco Santoro and Michele Samaja Istituto Scientifico San Raffaele, Istituto per le Malattie Cardiovascolari e Respiratorie and Dipartimento di Scienze e Tecnologie Biomediche, Università degli Studi di Milano, Milan
\end{abstract}

In order to study the haemodynamics of reperfusion injury in the posthypoxaemic heart, we exposed buffer-perfused isolated rat hearts to either: (1) 20-minute low-flow ischaemia or (2) 20-minute hypoxaemia followed by re-oxygenation and further ischaemia/reperfusion. In group 2, the myocardial contractility recovered less $(p<0.002)$ than in group 1 . This model therefore represents with sufficient reliability the clinical situation where hypoxaemic hearts are re-oxgenated before ischaemia/reperfusion and receive more severe injury than hearts exposed to ischaemia/reperfusion only. To locate the major site of the injury, further data were obtained (1) with infusion of superoxide dismutase and catalase during hypoxaemia and in the first five minutes of re-oxygenation, and (2) by eliminating re-oxygenation. It appears that the major determinant of reperfusion injury in hypoxaemic hearts is to be looked for in the events underlying hypoxaemia or re-oxygenation, and is mediated by oxygenderived free radicals.

\section{Introduction}

The application of modern techniques to protect the myocardium during surgical repair of cyanotic congenital heart disease has considerably decreased the mortality rate, but this rate still remains high $(5 \%)$ with respect to elective adult cardiac surgery. ${ }^{1-3}$ Several factors, normally ruled out in adults, may be responsible for this feature, including the age of the patient, ventricular

Address for correspondence: Michele Samaja. Dipartimento di Scienze e Tecnologie Biomediche, Istituto Scientifico San Raffaele, via Olgettina 60, 20132 Milano. Italy.

(c) Edward Arnold 1993 hypertrophy, the type of the surgical repair and the extent of cyanosis before cardiopulmonary bypass (CPB). ${ }^{4}$ At present, few experimental data are available to assess the importance of these factors. Nevertheless, several indications point to the cyanotic condition existing before the surgical repair as a candidate risk factor, ${ }^{1,5-7}$ but flexible and accessible in vitro or ex vivo experimental models to test this hypothesis are not available. Indeed. distinguishing hypoxaemia

\footnotetext{
*Current address: Pediatric Cardiac Surgery, Hospital 'S. Donato', Via Morandi 30. 20097 S. Donato Milanese, Milan, Italy.
} 
from ischaemia with full control of cardiac haemodynamics is difficult with in vivo models, and evidence of the critical role of cyanosis in such a clinical setting is therefore only indirect.

In this work, we describe a novel approach to the problem of the reperfusion injury in the posthypoxaemic myocardium. We exposed isolated perfused rat heart preparations to ischaemia/reperfusion (I/R), with and without previous exposure of the heart to hypoxaemia/reoxygenation $(H / R)$. The myocardial performance was continuously monitored during the various protocols with full control of the composition of the perfusate, the coronary perfusion rate, the loading conditions and the $\mathrm{O}_{2}$ supply. The purposes of this work were: (1) reproducing the in vivo situation under which a posthypoxaemic, cyanotic, re-oxygenated heart exposed to $I / R$ is injured with more severity than a normal heart exposed to I/R only; and (2) locating the major site of the injury. We will show that the oxygen derived free radicals (ODFR) generated during the re-oxygenation of hypoxaemic hearts and before I/R play a pivotal role in determining the injury of cyanotic hearts exposed to $\mathrm{I} / \mathrm{R}$.

\section{Materials and methods}

The experimental model used in this work is the isolated rat heart perfused through the aorta (Langendorff's model) with a crystalloid oxygenated buffer. The retrograde flow, regulated by an external pump, closes the aortic valve, displacing the perfusate through the coronary circulation. An inflatable balloon in the left ventricle keeps the loading conditions constant and allows measurement of myocardial performance.

Normothermic ischaemia or hypoxaemia were applied for the same time (20 minutes) reducing either the flow or the $\mathrm{pO}_{2}$ of the perfusate to $10 \%$ of baseline. At the end of hypoxaemia or ischaemia, the hearts were returned to baseline conditions to study the effects of the functional derangements which had occurred during the stress on myocardial performance.

The perfusing buffer was composed of 115.5 $\mathrm{mmol} \mathrm{NaCl}, 4.7 \mathrm{mmol} \mathrm{KCl}, 1.2 \mathrm{mmol} \mathrm{KH}_{2} \mathrm{PO}_{4}$, $0.5 \mathrm{mmol}$ EDTA, $1.2 \mathrm{mmol} \mathrm{Na}_{2} \mathrm{SO}_{4}, 28.5 \mathrm{mmol}$ $\mathrm{NaHCO}_{3}, 3 \mathrm{mmol} \mathrm{CaCl}, 1.2 \mathrm{mmol} \mathrm{MgCl}_{2}, 16.6$ mmol glucose, pH 7.4 and $37^{\circ} \mathrm{C}$. The buffer was equilibrated in two bubble oxygenators (Shiley S-100 A, Irvine) with either $94 \% \mathrm{O}_{2}+6 \% \mathrm{CO}_{2}$, or $9.4 \% \mathrm{O}_{2}+6 \% \mathrm{CO}_{2}$ (balance $\mathrm{N}_{2}$ ). A roller pump (Watson Marlow 503-S, Falmouth) forced the buffer through $8 \mu \mathrm{m}$ pore size polycarbonate filters to the aortic cannula at flow rates of 15 $\mathrm{ml} / \mathrm{min}$ or $1.5 \mathrm{ml} / \mathrm{min}$.

We used 33 hearts from male Sprague Dawley rats (weight $250-280 \mathrm{~g}$ ) anaesthetized by intraperitoneal heparinized sodium thiopental $(10 \mathrm{mg} / 100 \mathrm{~g}$ bodyweight $)$. The hearts were excised and mounted on the aortic cannula and retrograde perfusion was started immediately. An inflatable, saline-filled latex balloon was introduced into the left ventricle. Coronary pressure (CP) was monitored by a pressure transducer (Harvard apparatus 52-9966, Natick), connected to the aortic cannula. An additional transducer connected to the balloon provided the end-diastolic pressure (EDP), the left-ventricle developed pressure (LVDP) and the heart rate (HR). The integral of LVDP versus time ( $\oint$ LVDP) was evaluated recording the pressure wave of a single contraction by a digital storage oscilloscope (Nicolet Scientific Instruments 3091, Madison) and a chart recorder. The value for $\oint$ LVDP was then obtained by cutting off the area under the wave and weighing it with appropriate controls. The product $\oint \mathrm{LVDP} \times \mathrm{HR}$ is here considered an integrated index of the myocardial contractility since the hearts were not paced.

Data are expressed as mean \pm SE. Student's $t$ test, one-way ANOVA and the Bonferroni's tests were used as appropriate. The level of significance was set at $p=0.05$.

This investigation conformed with the Guide for the care and use of laboratory animals published by the US National Institutes of Health. (NIH publication No 85-23, revised 1985).

\section{Results}

For the purposes of this work, we performed two studies. Study 1 addressed the question as to whether the described experimental model is valid to represent with reasonable accuracy the situation occurring when a cyanotic heart is re-oxgenated and exposed to I/R. Hearts were stabilized for 30 minutes and then divided into two groups: $\mathrm{I} / \mathrm{R}$ and $\mathrm{H} / \mathrm{R}+\mathrm{I} / \mathrm{R}$ (Table 1 ). 
Table 1 Scheme of the experimental protocols of this study. The $\mathrm{O}_{2}$ supply during baseline and recovery was 14.1 $\mu \mathrm{mol} / \mathrm{min}\left(\mathrm{pO}_{2}=670 \mathrm{mmHg}\right.$ and coronary flow rate $\left.=15 \mathrm{ml} / \mathrm{min}\right)$. In hypoxaemia, $\mathrm{pO}_{2}$ was reduced to $67 \mathrm{mmHg}$ at constant coronary flow. In ischaemia, coronary flow was reduced to $1.5 \mathrm{ml} / \mathrm{min}$ at constant $\mathrm{pO}_{2}$. Under both conditions, therefore, the $\mathrm{O}_{2}$ supply was $1.41 \mu \mathrm{mol} / \mathrm{min}$.

Time (min)

\begin{tabular}{|c|c|c|c|c|c|c|}
\hline$\overline{\text { Group }(n)}$ & -30 & 0 & 20 & 40 & 60 & 80 \\
\hline $\begin{array}{l}I / R(7) \\
H / R+1 / R(9)\end{array}$ & $\begin{array}{l}\text { Baseline } \\
\text { Baseline }\end{array}$ & $\begin{array}{l}\text { Hypoxaemia } \\
\text { Ischaemia } \\
\leftarrow \text { SO }\end{array}$ & $\begin{array}{l}\text { Recovery } \\
\text { Recovery } \\
T^{*} \rightarrow\end{array}$ & Hypoxaemia & Recovery & \\
\hline $\begin{array}{l}\text { SOD/CAT (7) } \\
\text { H/l/R (10) }\end{array}$ & $\begin{array}{l}\text { Baseline } \\
\text { Baseline }\end{array}$ & $\begin{array}{l}\text { Hypoxaemı } \\
\text { Hypoxaemia }\end{array}$ & $\begin{array}{l}\text { Recovery } \\
\text { Ischaemia }\end{array}$ & $\begin{array}{l}\text { Ischaemia } \\
\text { Recovery }\end{array}$ & Recovery & \\
\hline
\end{tabular}

* Addition of $40 \mathrm{lU} / \mathrm{ml}$ superoxide dismutase and $104 \mathrm{lU} / \mathrm{m} /$ catalase starting at the fifth minute of hypoxaemia and ending at the fifth minute of recovery

Myocardial performance was compared at the end of the protocols to evaluate the effects of previous exposure to $H / R$ on $I / R$. Figure 1 shows that both diastolic and systolic performances were significantly depressed in the hearts of the latter group.

Study 2 was designed to investigate the role of re-oxygenation after hypoxaemia. For this purpose we devised three groups: H/R $+\mathrm{I} / \mathrm{R}$ (as in Study 1); SOD/CAT (hearts exposed to $\mathrm{H} / \mathrm{R}+\mathrm{I} / \mathrm{R}$ as in Study 1 , but with infusion of $40 \mathrm{IU} / \mathrm{ml}$ superoxide dismutase and 104 $\mathrm{IU} / \mathrm{ml}$ catalase starting at the fifth minute of hypoxaemia and ending at the fifth minute of recovery from hypoxaemia); $\mathrm{H} / \mathrm{I} / \mathrm{R}$ (hearts made ischaemic after hypoxaemia, eliminating the reoxygenation step).

Figure 2 shows the diastolic and systolic performances of these hearts. One-way, three-group ANOVA revealed highly significant differences among the various groups $(p<0.007)$. Invariably, the recovery of the hearts of the group H/R + I/R was always worse than that of the other two groups. In addition, no significant differences were observed between the recovery of hearts treated with superoxide dismutase and catalase and that of hearts which were not re-oxygenated before I/R.

\section{Discussion}

Using the experimental model described here, we monitored myocardial contractility under carefully controlled conditions of coronary
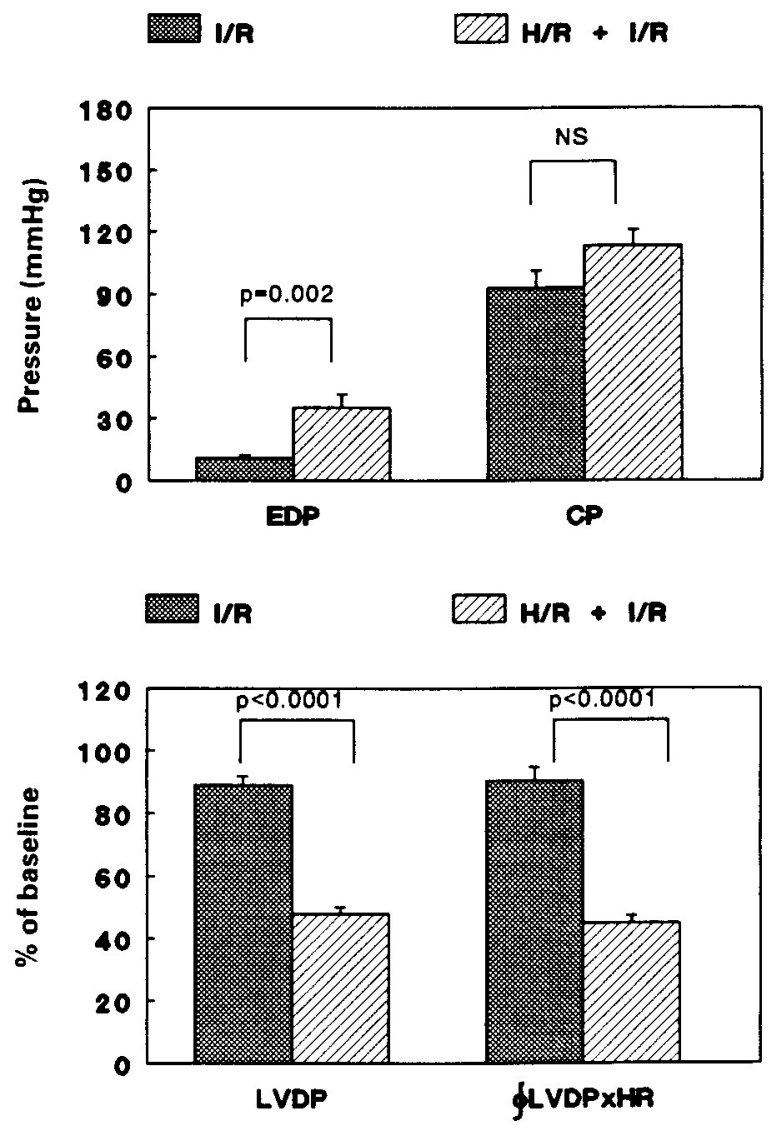

Figure 1 Myocardial performance (mean $\pm \mathrm{SE}$ ) at the recovery from $\mathrm{l} / \mathrm{R}(n=7)$ or $\mathrm{H} / \mathrm{R}+\mathrm{I} / \mathrm{R}(n=9)$. The significativity of the differences was evaluated using Student's $t$ test for unpaired data. EDP $=$ end-diastolic pressure, $\mathrm{CP}=$ coronary pressure, LVDP = left ventricle developed pressure, $\oint$ LVDP.HR = (time-pressure integral) $\cdot$ (heart rate). 
flow rate, $\mathrm{O}_{2}$ supply and composition of the perfusate. The fixed perfusate delivery rate prevented the autoregulation of the coronary flow by the hearts. The constant volume of the intraventricular balloon simulated constant loading conditions. The hearts were reperfused or re-oxgenated under the same conditions of baseline to study the effects of the metabolic and functional derangements driven by ischaemia and hypoxaemia on the myocardial recovery. The hearts were not paced and could therefore adjust their $\mathrm{O}_{2}$ and substrate demand, but the use of
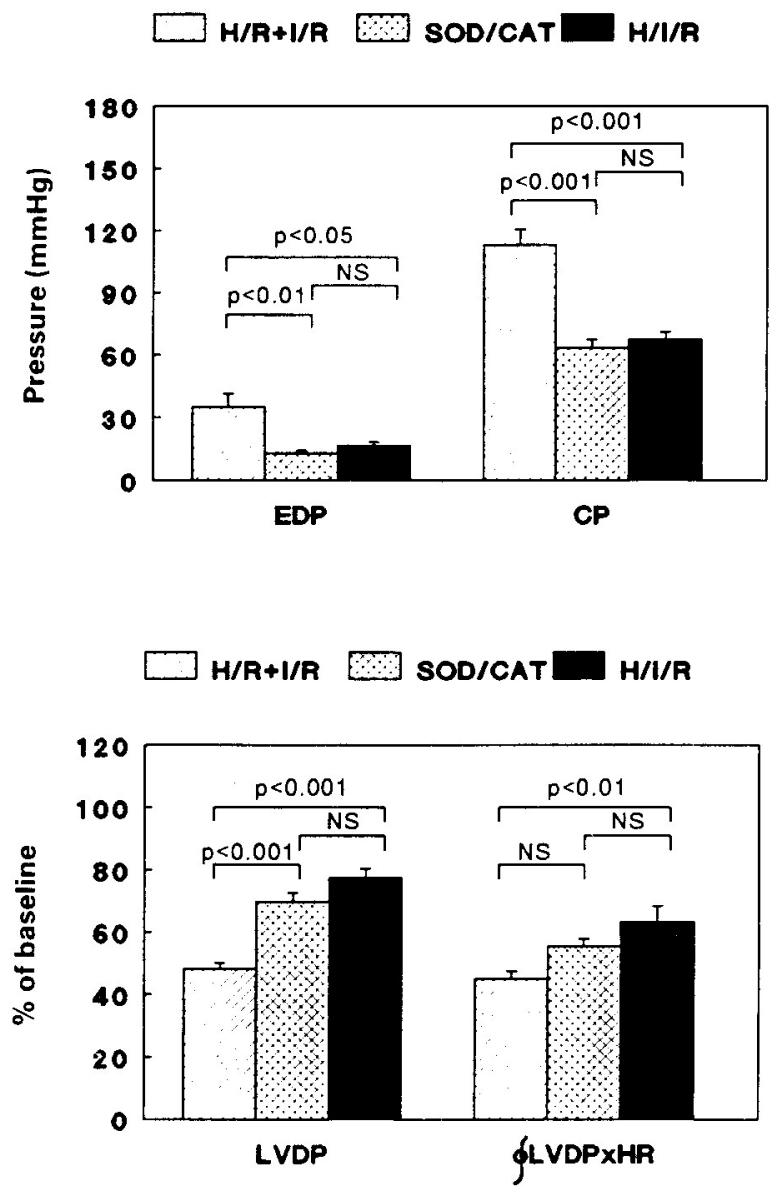

Figure 2 Same data as in Figure 1 in hearts from groups $H / R+I / R, S O D / C A T$ and H/l/R. One-way ANOVA analysis of these data yielded $p<0.007$. Bonferroni's test was used to define the significance of the differences (NS = not significant). the product (time-pressure integral) $\cdot$ (heart rate) $(\oint \mathrm{LVDP} \cdot \mathrm{HR})$ provided a reliable integrated measure of myocardial function. 8 The use of blood was discarded at the expense of a departure from physiological conditions, with the advantage of being able to correlate the applied stimuli to the heart responses with fewer interfering factors.

The protocol of the $H / R+I / R$ hearts is closely related to the sequence of events to which cyanotic, hypoxaemic hearts are exposed during most surgical procedures for repair of congenital heart disease: the hypoxaemic heart is first re-oxygenated at the beginning of the $\mathrm{CPB}$, then undergoes ischaemia with aortic cross-clamping for intracardiac repair, and is finally reperfused at the end of the procedure. This surgical protocol is often complicated by elevated hospital mortality regardless of the anatomical success of the intervention $1,4,7$ and the claimed increased tolerance of the neonatal heart to ischaemia with respect to the adult heart. 9,10

In our experimental model the hearts were exposed to acute hypoxaemia instead of the clinically more relevant situation of chronic hypoxaemia, limiting the meaning of the comparison between the two situations. Nevertheless, we believe that the present results may provide a partial explanation for the higher degree of severity found in paediatric, compared to adult, cardiac surgery.

Study 2 shows that the exposure of the H/R + I/R hearts to two stresses, compared to only one stress in $\mathrm{V} / \mathrm{R}$ hearts, may not be the only explanation for their more severe injury. In fact, two interventions that did not decrease the total time of hypoxaemia and ischaemia, i.e. treating the hearts with ODFR scavengers and eliminating reoxygenation, allowed hearts to recover as in the $\mathrm{I} / \mathrm{R}$ group. The re-oxygenation before ischaemia appeared the major site of oxidative injury in the hypoxaemic reperfused hearts. ${ }^{1,7}$ There is strong evidence for the involvement of ODFRs in this injury: (1) the final recovery was better in the presence of free radical scavengers; and (2) eliminating re-oxygenation allowed hearts to recover as with the scavengers. In the rat heart, ODFRs are mainly generated from xanthine oxidase and hypoxanthine. ${ }^{11-13}$ Although these radicals are generated for up to three hours after reperfusion, 14 they peak at two minutes after reflow consistently with the prevention of 
the oxidative injury by superoxide dismutase and catalase in the first five minutes of reoxygenation. The combined effects of superoxide dismutase and catalase on the prevention of ODFR-induced injury is known. ${ }^{15}$ The enzymatic activity of superoxide dismutase and catalase selected for this study approached the optimal. ${ }^{16,17}$

The hypothesis underlying this work is therefore that the intracellular generation of ODFRs during re-oxygenation is highly involved in determining the size of the reperfusion injury in posthypoxaemic re-oxygenated hearts and is consistent with the occurrence of the injury in the corresponding re-oxygenation of hypoxaemic tissues. ${ }^{18,19}$ Our observations are in agreement with the finding that during elective repair of tetralogy of Fallot, ODRF injury was observed before aortic cross-clamping, i.e. after re-oxygenation and before ischaemia. ${ }^{7}$ The reduced mitochondrial superoxide dismutase and glutathione peroxidase activities in hypoxaemia may be involved. ${ }^{20}$ However, the possibility that it is not hypoxaemia per se but hypoxaemia-derived abnormal loading characteristics which is the real factor leading to functional derangements in ischaemic hearts ${ }^{6}$ cannot be ruled out.

\section{Conclusions}

With this model, we could reproduce with reasonable accuracy the higher injury to which posthypoxaemic re-oxygenated hearts are exposed with respect to an ischaemic episode. Although it is difficult to transfer results gathered in an isolated heart preparation to an in vivo situation, it appears that the prevention of the oxidative portion of the injury appears feasible using adequate free radicals scavengers, but full protection of the heart is still to be worked out. The deleterious effect of low arterial $\mathrm{pO}_{2}$ in infants undergoing extracorporeal membrane oxygenation on the development of cardiac stun $^{21}$ emphasizes the importance of this issue. However, our knowledge of the mechanisms involved in ischaemia and hypoxaemia is still limited and important questions have yet to be answered, including the metabolic-functional interactions in the myocardium and the individual roles of the various factors in determining the size of the re-oxygenation or reperfusion injuries. The effect of chronic or sustained hypoxaemia must also be evaluated in order to offer more reliable explanations to the phenomena observed here.

\section{Acknowledgements}

We gratefully acknowledge the help provided by Sonia Allibardi and Stefania Casalini. This study was supported by a grant from the Target Project Biotechnology and Bioinstrumentation, Consiglio Nazionale delle Ricerche, Roma. Roberto Motterlini and Laura Brenna are fellows of the Fondazione San Romanello del Monte Tabor, Milano.

\section{References}

1 del Nido PJ, Mickle DAG, Wilson GJ et al. Inadequate myocardial protection with cold cardioplegic arrest during repair of tetralogy of Fallot. $J$ Thorac Cardiovasc Surg 1988; 95: 223-29.

2 Cosgrove DM, Loop FD, Lytle BW et al. Primary myocardial revascularization. Trend in surgical mortality. $J$ Thorac Cardiovasc Surg 1984: 88: 673-84.

3 Sanchez HE, Cornish EM, Shih FC et al. The surgical treatment of tetralogy of Fallot. Ann Thorac Surg 1984; 37: 431-36.

4 Bull C, Cooper J, Stark J. Cardioplegic protection of the child's heart. J Thorac Cardiovasc Surg 1984; 88: 287-93.

5 Silverman NA, Kohler J, Levitsky S, Pavel DG, Fang RB, Feinberg H. Chronic hypoxemia depresses global ventricular function and predisposes the depletion of high-energy phosphates during cardioplegic arrest: implications for surgical repair of cyanotic congenital heart defects. Ann Thorac Surg 1984; 37: 304-308.

6 Lupinetti FM, Wareing TH, Huddleston CB et al. Pathophysiology of chronic cyanosis in a canine model. Functional and metabolic response to global ischemia. J Thorac Cardiovasc Surg 1985: 90: 291-96.

7 del Nido PJ, Mickle DAG, Wilson GJ et al. Evidence of myocardial free radical injury during elective repair of tetralogy of Fallot. Circulation 1987; 76: 174-79.

8 Neely JR, Liebermeister H, Battersby EJ. Morgan $\mathrm{HE}$. Effect of pressure development on oxygen consumption by isolated rat heart. Am J Physiol 1967; 212: 804-14.

9 Ganzel BL, Katzmark SL, Mavroudis C. Myocardial preservation in the neonate. Beneficial effects of cardioplegia and systemic hypothermia on piglets undergoing cardiopulmonary bypass and myocardial ischemia. J Thorac Cardiovasc Surg 1988: 96: 414-22.

10 Kempsford RD, Hearse DJ. Protection of the immature myocardium during global ischemia. A comparison of four clinical cardioplegic solutions in 
the rabbit heart. J Thorac Cardiovasc Surg 1989; 97: 856-63.

11 Tarantola M, Motterlini R, Beretta M, Samaja M. Dual role of hypoxanthine in the reoxygenation of hypoxic isolated rat hearts. J Mol Cell Cardiol 1991; 23: $77-82$.

12 de Jong JW, van der Meer P, Nieukoop AS, Huizer T, Stroeve RJ, Bos E. Xanthine oxidoreductase activity in perfused hearts of various species, including humans. Circ Res 1990; 67: 770-73.

13 Downey JM, Hearse DJ, Yellon DM. The role of xanthine oxidase during myocardial ischemia in several species including man. J Mol Cell Cardiol 1988; 20: 55-63.

14 Bolli R, Patel BS, Jeroudi MO, Lai EK, McCay PB. Demonstration of free radical generation in stunned myocardium of intact dogs with the use of the spin trap $\alpha$-phenyl N-tert-butyl nitrone. J Clin Invest 1988; 82: 476-85.

15 Jeroudi MO, Triana FJ, Patel BS, Bolli R. Effect of superoxide dismutase and catalase, given separately, on myocardial 'stunning'. Am J Physiol 1990; 259: H889-901.

16 Bernier M, Manning AS, Hearse DJ. Reperfusion arrhythmias: dose-related protection by anti-free radical interventions. Am J Physiol 1989; 256: H1344-1352.

17 Jurmann MJ, Schaefers H, Dammenhayn L, Haverich A. Oxygen-derived free radical scavengers for amelioration of reperfusion damage in heart transplantation. J Thorac Cardiovasc Surg 1988; 95 : 368-77.

18 Corno AF, Laks H, Billingsley AM et al. The effects of acute hypoxia and reoxygenation on structure, metabolism and function of the isolated neonatal heart. J Thorac Cardiovasc Surg 1990; (in press)

19 McCord JM. Oxygen-derived free radicals in postischemic tissue injury. $N$ Engl J Med 1985; 312: $159-63$.

20 Guarnieri C, Flamigni F, Caldarera CM. Role of oxygen in the cellular damage induced by reoxygenation of hypoxemic hearts. $\mathrm{J} \mathrm{Mol} \mathrm{Cell} \mathrm{Cardiol}$ $1980 ; 12: 797-808$.

21 Martin GR, Short BL, Abbott C, O'Brien AM. Cardiac stun in infants undergoing extracorporeal membrane oxygenation. J Thorac Cardiovasc Surg 1991; 101: 607-11. 